\title{
Papel dos canais iônicos na Doença de Alzheimer
}

The role of ion channels in Alzheimer disease

\section{Maurus Marques de Almeida Holanda', Luiz Márcio de Brito Marinho Segundo르, Isac de Almeida Medeiros 3 , Bagnólia Araújo da Silva ${ }^{4}$}

\section{RESUMO}

A hipótese sobre a participação dos canais iônicos na patogênese da doença de Alzheimer (DA) sugere que o peptídeo beta-amilóide $(\mathrm{A} \beta)$, acumulado em placas depositadas no cérebro, provoque lesão ou até morte de neurônios pela formação de canais na membrana celular. Evidências encontradas em vários estudos têm demonstrado isso. O objetivo desta revisão é analisar o papel dos canais iônicos na fisiopatologia da DA.

Unitermos: Canais Iônicos. Doença de Alzheimer. Peptídeo. Terapia.

Citação: Holanda MMA, Segundo LMB M, Medeiros IA, Silva BA. Papel dos canais iônicos na Doença de Alzheimer.

\section{SUMMARY}

The hypothesis about the participation of ion channels in the pathogenesis of the Alzheimer disease (AD) suggests that the beta-amyloid peptide $(\mathrm{A} \beta)$, accumulated in plaques deposited in the brain, damages or even kills neurons by forming ion channels in cell membrane. Evidences found in several studies have been demonstrated this. The aim of the present revision is to analyze the role of ion channels in $\mathrm{AD}$ `s physiopathology.

Keywords: Ion Channels. Alzheimer Disease. Peptide. Therapy.

Citation: Holanda MMA, Segundo LMB M, Medeiros IA, Silva BA. The role of ion channels in Alzheimer disease.
Trabalho realizado no Laboratório de Tecnologia Farmacêutica (LTF) da Universidade Federal da Paraíba (UFPB).

1.Neurocirurgião, Professor Substituto da Disciplina de Neurologia da UFPB Doutor em Farmacologia pela UFPB.

2.Acadêmico de Medicina da UFPB.

3.Farmacologista, Professor Doutor da UFPB.

4.Farmacologista, Professora Doutora da UFPB.
Endereço para Correspondência: Maurus MA Holanda R. Santos Coelho Neto, 200/802.

CEP 58038-450, João Pessoa-PB E-mail: maurusholanda@hotmail.com 


\section{INTRODUÇÃO}

A doença de Alzheimer (DA) foi primeiro descrita, no início do século XIX, como patologia, por Alois Alzheimer (1864-1915), neurologista alemão, observando como características uma doença que provoca progressiva deterioração das funções cognitivas e comportamentais, como diminuição da memória, da linguagem, da razão e da habilidade de cuidar de si próprio ${ }^{1}$. Representa mais de 50\% dos casos de todas as demências. Cerca de $1 \%$ das pessoas com mais de 65 anos e $25 \%$ com mais de 85 anos podem apresentar algum sintoma dessa enfermidade e são inúmeros os casos que evoluem para demência ${ }^{2}$.

O termo "demência" não deve ser utilizado como sinônimo de DA, já que esta última corresponde a uma síndrome "degenerativa" e "progressiva", enquanto aquele é mais abrangente, sendo, às vezes, utilizado em quadros que se seguem à isquemia cerebral ou condições reversíveis, como secundária à medicação ou depressão $0^{3,4}$.

Já que o quadro clínico da DA deve-se às disfunções celulares no cérebro e às alterações moleculares $^{5}$, avanços recentes na compreensão desse processo criaram oportunidades para intervenções farmacológicas nos seus estágios iniciais.

O objetivo desta revisão é analisar o papel dos canais iônicos na fisiopatologia da DA, integrando os mecanismos moleculares que levam ao dano celular, chamando atenção para novas ferramentas terapêuticas que poderão atuar antes da formação dos canais e no decorrer da cascata degenerativa que culmina com a apoptose neuronal.

\section{Peptídio Beta-Amilóide}

O elemento primordial na patogênese da doença de Alzheimer é a deposição de peptídeo $\beta$-amilóide $(\mathrm{A} \beta)$ no cérebro. $A \beta$ é derivado da grande proteína transmembranosa precursora de amilóide (PPA), sendo um peptídeo com 40 a 42 aminoácidos. São duas as principais vias de metabolismo da PPA em indivíduos saudáveis. $\mathrm{O}$ aumento do metabolismo de uma dessas vias, a via amiloidogênica, forma o composto $A \beta 42$, que é relativamente insolúvel e agrega-se, de preferência, em uma configuração pregueada $\beta$. Nesta forma agregada insolúvel, o A $\beta$ é neurotóxico e causa morte celular por apoptose in vitro ${ }^{6.9}$.

Algumas mutações genéticas promovem o metabolismo amiloidogênico, sendo que a expressão da PPA parece aumentar por dano neuronal ou estresse oxidativo/isquêmico ${ }^{8}$. É o que ocorre pela trissomia do gene da PPA no cromossomo 21, como os eventos citotóxicos que causam aumento do cálcio intracelular ${ }^{10,11}$.

As alterações histopatológicas da DA são caracterizadas pela presença das placas senis (PS) e dos emaranhados neurofibrilares (ENF) no neocórtex e no hipocampo. Outras características neuropatológicas incluem degeneração neurovacuolar e deposição de $A \beta$ nas paredes de pequenos vasos sanguíneos corticais?

As PS não são constituídas por uma proteína única derivada da PPA, são estruturas extracelulares compostas por um núcleo de fibrilas de $\mathrm{A} \beta$, circundado por neurônios distróficos, astrócitos e micróglia. Muitas proteínas como proteases, inibidoras de proteases e proteínas associadas a microtúbulos, como a tau, são depositadas nas placas. A apolipoproteína $\mathrm{E}(\mathrm{ApoE})$ também está relacionada às $\mathrm{PS}^{12}$. Já foi inclusive demonstrada maior prevalência de DA associada ao polimorfismo de genes relacionados ao metabolismo do colesterol, dentre eles o gene da $\mathrm{ApoE}^{13}$. Na DA, a densidade de ENF, que contêm a proteína associada a microtúbulos tau, no neocórtex, tem relação com a gravidade da demência; contudo os depósitos associados à idade estão presentes no hipocampo e no córtex temporal inferior em indivíduos sem demência. Os emaranhados se acumulam em resposta a uma variedade de lesões cerebrais degenerativas, tóxicas e traumáticas ${ }^{11,12}$.

$\mathrm{Na} \mathrm{DA}$, ocorre redução e morte neuronal progressiva, acometendo várias áreas encefálicas, inclusive hipocampo, tronco cerebral, prosencéfalo basal e áreas frontal e têmporo-parietal do neocórtex. Em geral, esses eventos causam atrofia cortical difusa e dilatação dos ventrículos nos estágios mais avançados ${ }^{14}$.

A lesão neuronal na DA depende de vários fatores relacionados, entre eles a evidência de que os radicais livres possam estar envolvidos na promoção de agregação de $\mathrm{A} \beta$, pois os antioxidantes inibem a formação de fibrilas de $A \beta$, podendo aumentar a formação de radicais livres que danificam as membranas celulares e causam alterações na homeostase do cálcio ${ }^{10}$. Pesquisas recentes identificaram que o $\mathrm{A} \beta$ acumulado em placas promove formação de canais iônicos nas membranas das células cerebrais na $\mathrm{DA}^{15}$.

\section{Papel do $A \beta$ na formação dos canais iônicos}

Um grande número de evidências coloca o $A \beta$ entre as principais causas do desenvolvimento da patologia de Alzheimer:

- Casos familiares herdados da doença de Alzheimer freqüentemente têm uma mutação genética, próxima ao sítio da $\beta$-secretase, na $\mathrm{PPA}^{16}$. 
- Depósitos de $A \beta$ são universalmente associados à $\mathrm{DA}$ e aparecem proporcionalmente à gravidade da doença, medida pelo déficit cognitivo ${ }^{11,12}$.

- Trissomia do gene da PPA, no cromossomo 21, leva ao aumento precoce de depósitos amilóides e demência precoce em pacientes com Síndrome de Down ${ }^{17}$.

- Infusão ou expressão transgênica de $A \beta$ causadoença de "Alzheimer-like" emanimais com depósitos de amilóide, perda de sinapses e déficit cognitivo e comportamental ${ }^{18}$.

- Muitos estudos mostram que o A $\beta$ pode inibir o processo envolvendo a memória, além de ser neurotóxico aos neurônios e outras células ${ }^{10,14}$.

- Evidências de muitos laboratórios têm demonstrado que $A \beta$ pode formar canais iônicos em: bicamada lipídica, lisossomos, neurônios, oócitos e células endoteliais ${ }^{15,19,20}$.

- Vacinação contra $A \beta$ previne ou reverte esta síndrome (doença de "Alzheimer-like") em ratos ${ }^{21}$.

\section{Mecanismo de lesão celular pelos canais iônicos}

Os canais iônicos, quando formados pelo $A \beta$ na membrana plasmática dos neurônios, são perigosos porque lesam estas células, que precisam manter gradientes iônicos e um potencial permanente em toda sinalização. Mesmo pequenas quedas no potencial de membrana podem alterar a propriedade do potencial de ação, do limiar de disparo e do potencial de repouso neuronais e levar à disfunção neurológica, como quadro demencial, pela alteração do influxo de íons ${ }^{22-24}$.

Estes canais possuem características fisiopatológicas próprias que podem ser consistentes com suas propriedades tóxicas. São heterogêneos e diferem, entre si, quanto ao tamanho, forma, seletividade, bloqueio e abertura ${ }^{22-24}$.

Observações quanto ao tamanho foram demonstradas nos estudos de Lin et al. ${ }^{23}$, usando microscópio de força atômica, que pode ser operado para visualizar a microestrutura da membrana plasmática, mostrando que estes canais apresentam tamanho variado, sendo geralmente grande, seja com 4 ou com 6 sub-unidades, adquirindo respectivamente forma quadrangular ou hexagonal. De acordo com Abramov et al. ${ }^{22}$, estes canais iônicos formados são pouco seletivos à passagem de íons. Porém, apesar desse trabalho só evidenciar seletividade aos íons cálcio $\left(\mathrm{Ca}^{+}\right)$, Kagan et al. ${ }^{15}$ e Arispe et al. ${ }^{25}$ mostraram que além do $\mathrm{Ca}^{+}$, admitem passagem dos íons sódio $\left(\mathrm{Na}^{+}\right)$, potássio $\left(\mathrm{K}^{+}\right)$, césio $\left(\mathrm{Cs}^{+}\right)$, lítio $\left(\mathrm{Li}^{+}\right)$e, possivelmente, cloreto $(\mathrm{Cl})$.
Estes canais não sofrem ação dos bloqueadores dos canais de cálcio, porém são bloqueados reversivelmente pelos íons zinco $\left(\mathrm{Zn}^{+2}\right)$, trometamina (tris) e, irreversivelmente, pelo íon alumínio $\left(\mathrm{Al}^{+3}\right)$, acreditando-se, assim, que o zinco tenha papel importante que impeça a formação da placa pelo $A \beta^{22}$. Estudos prévios de outros laboratórios, citados por Lin et al. ${ }^{23}$, demonstram que muitos bloqueadores dos canais de cálcio e antagonistas de mobilização do cálcio, como: $\omega$-conotoxina, nifedipina, verapamil, APV, MK-801, cAMP, 8-bromo cAMP e cGMP, não inibiram a neurotoxicidade induzida pelo $A \beta 25$ 35 e A $\beta 1-40$. Por isso é difícil excluir a possibilidade do influxo de cálcio por um canal pré-existente, pois a inibição da degeneração celular pelo zinco sugere que a toxicidade do $A \beta$ é mediada pelo influxo do $\mathrm{Ca}^{+2}$ via canais $A \beta$. Curiosamente, o vermelho congo, corante aniônico metacromático utilizado para evidenciar a presença de amilóide nos tecidos, inibe a agregação, a neurotoxicidade e a formação de canais, mas não bloqueia canais já inseridos nas membranas. Entre outras características dos canais iônicos, eles também são voltagem-independentes ${ }^{22}$.

$\mathrm{O}$ grande canal de $\mathrm{A} \beta$ pobremente seletivo e de vida longa pode degradar potencial de membrana gerado pelos canais seletivos de $\mathrm{K}^{+}$em neurônios ${ }^{15}$. Ye et al. ${ }^{26}$ confirmaram que protofibrilas de $\mathrm{A} \beta$ podem inibir correntes específicas de $\mathrm{K}^{+}$em culturas de córtex de embrião de ratos, mostrando que pode ter alguma implicação na DA.

A permeabilidade ao $\mathrm{Ca}^{+2}$ dos canais de $\mathrm{A} \beta$ pode levar à apoptose e sinalização aberrante. Foi calculado que um único canal de $\mathrm{A} \beta 1-40$ de 4 subunidades pode causar passagem do $\mathrm{Na}^{+}$, provocando mudanças significativas no gradiente iônico intracelular. Foi previsto que o vazamento de $\mathrm{Ca}^{+2}, \mathrm{Na}^{+}$e $\mathrm{K}^{+}$pode ter sérias conseqüências para a homeostase celular em poucos segundos. A degradação do potencial de membrana pode também aumentar o influxo de $\mathrm{Ca}^{+2}$ pelos canais de $\mathrm{Ca}^{+2}$ sensíveis à voltagem na membrana celular. Cálculos semelhantes demonstraram que outros canais formados por toxinas podem matar bactérias ou células rapidamente somente pela via de vazamento de íons ${ }^{27}$, reforçando a idéia de que o vazamento de diversos íons através dos canais formados pelo $\mathrm{A} \beta$ pode levar à morte de células encefálicas, sendo esse fato importante na gênese da DA.

A desregulação da homeostase do $\mathrm{Ca}^{+2}$ e a produção de radicais livres (estresse oxidativo) são elementos-chave da neurotoxicicidade ${ }^{14,28}$. Trabalhos atuais mostram que um mecanismo tóxico potencial 
foi estabelecido para o $A \beta$, alterando a atividade enzimática intracelular, com conseqüente estresse oxidativo dependente do cálcio extracelular. Alguns exemplos de enzimas envolvidas no metabolismo intermediário na DA que estão diminuídas são: NADPH-oxidase, glutamina-sintetase, creatina-cinase, $\mathrm{DPH}$, aconitase, a-KGDH. Sendo evidenciado que, a primeira, quando ativada, levou a um estresse oxidativo intracelular, ou seja, o acúmulo de espécies reativas de oxigênio que causam danos à estrutura das biomoléculas, culminando com a depleção do glutation, agente anti-oxidante intracelular, tanto nos astrócitos como nos neurônios circunvizinhos, e, conseqüentemente, com apoptose ${ }^{22}$.

Outra via descrita por Mattson et al. ${ }^{14}$, envolvendo o $A \beta$, demonstrou que esse peptídeo interfere nas ATPases de movimentação iônica na membrana, na movimentação ativa de glicose, nos transportadores de glutamato, aumentando o influxo de $\mathrm{Ca}^{+2}$ pelos canais dependente de voltagem e operados por ligantes. E em alguns casos de DA familiar causada por mutações no gene da presenilina 1 e 2 , localizados respectivamente nos cromossomos 14 e 1 e responsáveis por alterar a homeostase do $\mathrm{Ca}^{+2}$ do retículo endoplasmático, há grande quantidade de $\mathrm{Ca}^{+2}$ liberada por estimulação, possivelmente em decorrência da alteração dos receptores de canais de IP3 e de rianodina, $\mathrm{Ca}^{+2}$ ATPase e a proteína Herp ${ }^{14,29}$. Neste mesmo artigo de Mattson et al. ${ }^{14}$, são evidenciadas anormalidades da regulação do $\mathrm{Ca}^{+2}$ em astrócitos, oligodendrócitos e micróglia num modelo experimental de DA. Há expressão da PPA modificada e mutações da presenilina alterando a homeostase do $\mathrm{Ca}^{+2}$ intracelular, o que pode contribuir para a disfunção e morte neuronal, onde $\mathrm{o} A \beta$ pode induzir à ativação celular e produção de citocinas inflamatórias em astrócitos e micróglia e pode também lesar e matar oligodendrócitos ${ }^{8,14}$.

\section{Mitocôndria e influência do Ph na formação do canal}

Tem sido sugerido que o $\mathrm{A} \beta$ aumenta a produção de espécies reativas de oxigênio (íons oxigênio, radicais livres e peróxidos) na mitocôndria por lesão da cadeia respiratória mitocondrial ${ }^{22}$. Alternativamente, canais formados pelos $A \beta$ podem se inserir em membranas mitocondriais e levar à apoptose. A dinâmica dos experimentos está em investigação ${ }^{30}$.

É sugerido que a formação de canais pelo $A \beta$ pode ocorrer preferencialmente em compartimentos de $\mathrm{pH}$ baixo, como nos lisossomos, que liberam componentes tóxicos no citosol quando sinalizados.
É bom lembrar que estes mecanismos não são exclusivos e que a formação dos canais pode iniciar lesão por múltiplas vias ${ }^{22}$.

\section{Terapias emergentes}

A DA tem como etiologia fatores genéticos e ambientais, que interagem de forma complexa. É preciso que se elucidem os principais fatores de risco ambientais, para que a prevenção primária seja eficaz.

Tendo em vista sinais de depleção de neurotransmissores, processo inflamatório e estresse oxidativo na fisiopatogenia da DA, é provável que o seu manejo seja com o uso de drogas de reposição de neurotransmissores associadas a AINEs e a antioxidantes, atuando sobre o metabolismo do A $\beta$. Devem-se, ainda, testar a eficácia e as interações dessas associações ${ }^{7}$. Estão sendo pesquisadas drogas que atuem na agregação do $A \beta$ e conseqüente formação dos canais iônicos. Atualmente, está em fase clínica um estudo com quelante de metais pesados, o clioquinol, um anti-malárico que impede a formação desses canais e conseqüente influxo de cálcio ${ }^{22}$. Na medida em que tratamentos mais eficazes estiverem disponíveis, os estudos para identificar os indivíduos sob risco tornar-se-ão mais importantes, devendo incluir testes de identificação de marcadores genéticos e biológicos da DA, devendo-se também levar em conta que qualquer tratamento medicamentoso deverá ser utilizado junto com intervenções sociais, ambientais e comportamentais ${ }^{7}$.

\section{REFERÊNCIAS BIBLIOGRÁFICAS}

1. Perry RJ, Hodges JR. Attention and executive deficits in Alzheimer`s disease: a critical review. Brain 1999;122:383-404.

2. Fratiglioni L, Launer LJ, Andersen K, Breteler MM, Copeland JR, Dartigues JF, et al. Incidence of dementia and major subtypes in Europe: a collaborative study of population-based cohorts. Neurology 2000;54(11 suppl 5):S10-5.

3. Gorelick PB, Nyenhuis DL, Garron DC, Cochran E. Is vascular dementia really Alzheimer`s disease or mixed dementia? Neuroepidemiol 1996;15(6):286-90.

4. Alexopoulus GS, Young RC, Meyers BS. Geriatric depression: age of onset and dementia. Biol Psychiatr 1993;34(3):141-5.

5. Iraizoz I, Guijarro JL, Gonzalo LM, Lacalle S. Neuropathological changes in the nucleus basalis correlate with clinical measures of dementia. Acta Neuropathol 1999;98(2):186-96.

6. Selkoe DJ. Alzheimer`s disease: genotypes, phenotypes and treatments. Science 1997;275(5300):630-1.

7. Kelly C. Manual da doença de Alzheimer. Espanha: Merit Publishing International, 2003, 53.

8. Pearson HA, Peers C. Physiological for amyloid $\beta$ peptides. J Physiol 2006;575(1):5-10. 
9. Reinhard C, Hébert SS, De Strooper B. The amyloid-beta precursor protein: integrating structure with biological function. EMBO J 2005;24(23):3996-4006.

10. Carr DB, Goate A, Morris C. Current concepts in the pathogenesis of Alzheimer`s disease. Am J Med 1997;103(3A):3S-10S.

11. Cummings JL, Mega M. Alzheimer`s disease: etiologies and pathogenesis. Consult Pharm 1996;11(suppl E):8-15.

12. Parihar MS, Hemnani T. Alzheimer`s disease pathogenesis and therapeutic interventions. J Clin Neurosci 2004;11(5): 456-67.

13. Gong JS, Morita S, Kobayashi M, Handa T, Fujita SC, Yanagisawa $\mathrm{K}$, et al. Novel action of apolipoprotein $\mathrm{E}$ (ApoE): ApoE isoform specifically inhibits lipid-particle-mediated cholesterol release from neurons. Mol Neurodegener 2007;2:9.

14. Mattson MP, Chan SL. Neuronal and glial calcium signaling in Alzheimer`s disease. Cell Calcium 2003;34(4-5):385-97.

15. Kagan BL, Hirakura Y, Azimov R, Azimova R, Lin MC. The channel hypothesis of Alzheimer`s disease: current status. Peptides 2002;23(7):1311-5. 16. Mullan M, Crawford F. Genetic and molecular advances in Alzheimer`s disease. Trends Neurosci 1993;16(10):398-403.

17. Scheuner D, Eckman C, Jensen M, Song X, Citron M, Suzuki N, et al. Secreted amyloid beta-protein similar to that in senile plaques of Alzheimer `s disease is increased in vivo by presenilin 1 and 2 and APP mutations linked to familial Alzheimer`s disease. Nat Med 1996;2(8):864-70.

18. Hsiao K, Chapman P, Nilsen S, Eckman C, Harigaya YS, Yang F, et al. Correlative memory deficits, $A \beta$ elevation and amyloid plaques in transgenic mice. Science 1996;274(5284):99-102.

19. Kawahara M, Arispe N, Kuroda Y, Rojas E. Alzheimer`s disease amyloid-beta protein forms $\mathrm{Zn}^{2+}$-sensitive, cation selective channels across excised membrane patches from hypothalamic neurons. Biophys J 1997;73(1):67-75.
20. Fraser SP, Suh YH, Djamgoz MB. Ionic effects of the Alzheimer `s disease beta-amyloid precursor protein and its metabolic fragments. Trends Neurosci 1997;20(2):67-72.

21. Schenk DB, Seubert P. Beta-peptide immunization: a possible new treatment for Alzheimer disease. Arch Neurol 2000;57(7):934-6.

22. Abramov AV, Canevari L, Duchen MR. Calcium signals induced by amyloid beta peptide and their consequences in neurons and astrocytes in culture. Biochim Biophys Acta 2004;1742(1-3):81-7.

23. Lin H, Bhatia R, Lal R. Amyloid $\beta$ protein forms ion channels: implications for Alzheimer`s disease pathophysiology. FASEB J 2001;15(13):2433-44.

24. Plein H. Amyloid beta protein forms ion channels. Trends Neurosci 2002;25(3):137.

25. Arispe N, Pollard HB, Rojas E. Giant multilevel cation channels formed by Alzheimer disease amyloid $\beta$-protein $[\mathrm{A} \beta \mathrm{P}-(1-40)]$ in bilayer membranes. Proc Natl Acad Sci USA 1993;90(20):10573-7.

26. Ye CP, Selkoe DI, Hartley DM. Protofibrils of amyloid beta-protein inhibit specific $\mathrm{K}^{+}$currents in neocortical cultures. Neurobiol Dis 2003;13(3):177-90.

27. Schein SJ, Kagan BL, Finkelstein A. Colicin K acts by forming voltage dependent channels in phospholipid bilayer membranes. Nature 1978;276(5684):159-63.

28. Butterfield DA, Hensley K, Harris M, Mattson M, Carney J. Betaamyloid peptide free radical fragments initiate synaptosomal lipoperoxidation in a sequence-specific fashion: implications to Alzheimer`s disease. Biochem Biophys Res Commun 1994;200(2):710-5.

29. Nelson O, Tu H, Lei T, Bentahir M, De Strooper B, Bezprozvanny I. Familial Alzheimer disease-linked mutations specifically disrupt $\mathrm{Ca} 2+$ leak function of presenilin 1. J Clin Invest 2007;117(5):1230-9.

30. Reed JC. Mechanisms of apoptosis. Am J Pathol 2000;157(5):1415-30. 